\title{
СИМВОЛИЧЕСКИЕ ПАТТЕРНЫ СУБЪЕКТИВНОЙ ОЦЕНКИ БУДУЩЕГО СОВРЕМЕННОЙ МОЛОДЕЖЬЮ РОССИИ
}

\author{
Русанова Анна Александровна, \\ ollyvost@tpu.ru \\ Конюхова Татьяна Васильевна, \\ konykhova@tpu.ru \\ Национальный исследовательский Томский политехнический университет, \\ Россия, 634050, г. Томск, пр. Ленина, 30.
}

Русанова Анна Александровна, аспирант отделения социально-гуманитарных наук Школы базовой инженерной подготовки, инженер организационного отдела Инженерной школы информационных технологий и робототехники Национального исследовательского Томского политехнического университета.

Конюхова Татьяна Васильевна, кандидат философских наук, доцент отделения социальногуманитарных наук Школы базовой инженерной подготовки Национального исследовательского Томского политехнического университета.

Актуальность темы междисциплинарного осмысления символических паттернов будущего молодежью России определяется потребностью в самовыражении собственного восприятия будущего у молодого поколения через социальные коммуникации и отсутствием социально-философских работ, посвященных анализу взаимодействий между элементами познавательных аспектов и представлений о будущем в конкретных символах. Цель работы: определить символические реалии современной российской молодежи, репрезентативным свойством отражения которых на данный момент являются молодежные СМИ. Методы анализа: контент-анализ (качественный и количественный) молодежных СМИ развлекательного характера вместе с методологией социального конструктивизма для установления релятивных символических паттернов образов будущего в представлении молодого поколения. Результаты. Было установлено, что процесс конструирования концепта «образ будущего» происходит на субъективном уровне, а символ как фрагмент мышления находит отражение в современных молодежных СМИ, в рамках которых процессы знаковой динамики рефлексируют и задают правила конструирования действительности. Также исследование позволило описать триггерные точки (оптимистическая оценка личного и общего будущего России) в субъективном символизме, где главной конструирующей силой является непосредственный субъект (интервьюируемый студент) в контексте различных компонентов. При анализе молодежных изданий было выявлено, что взаимодействие субъективного представления молодежи об образах будущего, коррелирующего с усиливающейся ролью социальных медиа, отражает положительную динамику представлений относительно будущего России в студенческом сообществе, но при этом показывает низкую вовлеченность молодого поколения страны в коллективные цели, в выстраивание идеи общего российского будущего в паттернах положительной направленности. Отмечается, что маркер «Карьера» отображается в качестве основной триггерной точки, которая является ключевым показателем собственного будущего для молодого поколения.

Ключевые слова: Социальная философия, символ, молодежь, образ будущего, контент-анализ.

На протяжении длительного времени в российском обществе, в особенности у современной молодежи, присутствовала определенная неоднозначность в представляе- 
мых образах относительно как личностного, так и общего будущего России, что доказывается множеством проведенных исследований [1-5]. Все больше проблем поднимается с позиций визуализации собственного будущего у молодежи в России (прототипирование, игровая форма воспроизводства, видеоблогинг и пр.). Немаловажным определяется фактор наличия социальной реальности в современных молодежных социальных коммуникациях, где основной «движущей» силой становится именно субъект как актор, конструирующий собственную реальность. Социологические исследования прошлых лет констатировали наличие коллективных страхов по отношению как к собственному будущему, так и к общему будущему России у молодого поколения [6, с. 7-9]. При этом субъективизм символических паттернов данной оценки является малоизученным с позиции социальной философии, которая способна не только проанализировать конструирующую силу символической социальной реальности личности, но и определить уровень трансформации современного коммуникативного пространства в молодежной среде.

Неотъемлемым условием рассмотрения образа будущего являются как временные, так социальные детерминанты, которые, в свою очередь, тоже становятся конструктом, свойственным как отдельной личности, так и социуму в целом. Однако не стоит рассматривать будущее в субъективном восприятии только относительно самой личности, т. к. следует учитывать тот факт, что в сознании современной молодежи конструируется и своеобразный субъективный образ будущего всей станы, что вкупе влияет на определенные установки относительно динамики развития общества.

Современность тесно связана распространением информационнокоммуникационных технологий, играющих существенную роль в процессах самоопределения личности, развития межсубъектных отношений и пр. Многие исследователи возлагают определенный уровень ответственности за культурные «изломы» именно на современные СМИ вследствие их глобализационного характера [7, с. 115]. Двусторонний способ обмена и воздействия информации изменяет и самого человека и становится изменяющей, конструирующей силой субъекта, формируя новое представление о чем-либо. При этом новая, дигитальная культура, накладывает свой отпечаток на несформированную область сознания молодого поколения [8, с. 126-127]. Коммуникативное пространство личности (включая блоги, журналы, статьи в социальных сетях и прочее) отражает своеобразное субъективное миропонимание, в которое погружен индивид, формируя новую коммуникативную парадигму. У. Эко полагал, что в эпоху цифровых коммуникаций именно «виртуальный» канал (интернет-источники) является наиболее успешным по своему воздействию, т. к. у личности появляется «выбор» объемов и структуры представляемых данных [9, с. 6-8].

Именно поэтому в эпоху информационного общества важное место в анализе репрезентируемых в СМИ данных об образах будущего является поиск современных систем ценностей, направленных на взаимосвязанность образов прошлого, настоящего и будущего для построения цельной картины мира молодежи. И именно трансдисциплинарный подход в изучении многообразного мира современной молодежи поможет исследовать и сопоставить представление об образах будущего в субъективном его понимании.

Ярким репрезентативным свойством молодежной культуры как носителя символических форм являются современные СМИ, ориентированные на молодежную аудиторию и которые, соответственно, могут частично отражать представления о собственном и коллективном будущем самой молодежи. Молодежную субкультуру и ее способы существования через определенные формы рассматривали такие исследователи, как 
М. Мид, У. Эко, Ю. Хабермас, Д. Даунс, в определенной мере в своей теории «архива» говорили о субъективном пространстве символической интерпретации языка М. Фуко, Т.Г. Исламшина, Н. Шведтнер и т. д. Ю. Хабермас отмечал индивидуальную саморепрезентирующую силу субъекта: «Индивидуальность объясняется с помощью того факта, что каждая самопрезентирующая субъективность сосредоточена на самой себе и представляет мир как целое своим собственным уникальным способом» [10, с. 42]. П. Брегер говорил о том, что «...индивидуализм, если даже взглянуть на него как на идею..., обладает и познавательными и нормативными аспектами. Такое понятие определяет основное свойство людей: они - самостоятельные личности с индивидуальными качествами, выходящими за рамки коллективных признаков» [11, с. 116-117]. Таким образом, следует, что процесс конструирования концепта «образ будущего» происходит на индивидуальном, сугубо субъективном уровне.

Прежде чем рассматривать символические паттерны субъективной оценки будущего российской молодежью в современном коммуникативном пространстве, необходимо обратиться к социально-философскому пониманию конструирующей силы символа.

Социально-философская мысль XX в. говорит об имманентной способности человека существовать в рамках символического мышления и взаимодействия с природой, другими людьми и социумом. Данный «обмен» происходит вследствие того, что человеческий разум символически функционирует и некоторые компоненты этого опыта формируют отношение к другим компонентам (символам), как, к примеру, говорил А.Н. Уайтхед [12, с. 132; 21, с. 1444-1447]. Академик РАН В.С. Степин отметил первостепенность субъекта с его ценностными установками в постнеклассической рациональности [13]. Вследствие перестановки акцентов в постнеклассической научной парадигме мышления личность является уже неотъемлемым элементом открытых самоорганизующихся систем [12, с. 133]. Данный вывод также определяет ключевую роль человека в социокультурных системах, в процессах знаковой динамики, поскольку он существует в знаково-символическом пространстве.

В основе современного представления о мире лежат визуальные образы, символы, репрезентирующие представление о реальности, т. к. человек по своей сущности позиционируется как «Ноmo significans» [14, с. $160 ; 15$, с. 27-28; 16, с. 36-37]. Согласно многим работам по символизму, человек порождает и воспринимает символы, т. к. символ в широком понимании, является интеллектуальным инструментом культуры (о чем говорили Э. Кассирер, А.Н. Уайтхед, С. Лангер, У. Эко, М. Фуко и др.). Символ как фрагмент мышления находит свою рефлексию и в современных молодежных СМИ, в рамках которых процессы знаковой динамики отражают и задают правила конструирования действительности (а средством конструирования реальности выступают именно социальные коммуникации).

Несомненным фактом является утверждение, согласно которому коммуникативное пространство способно изменять личность, его понимание своего места в мире. Именно благодаря ориентированности на свою собственную индивидуальность российский студент (как представитель молодого поколения) получает возможность усваивать все возрастающий объем информации относительно будущего как собственного, так и общего $[17$, с. $112 ; 20$, с. 154-155]. Конструирующую силу субъекта отражают работы представителей течения социального конструктивизма. П. Бергер и Т. Лукман [18] полагали, что индивидуумы принимают активное участие в самостоятельном создании воспринимаемой ими социальной реальности, т. е. способны сами создавать смыслопорождающие символы, примером чему может послужить бесчисленное количество «ме- 
мов» как феноменов культуры молодежи, которые отражают сугубо субъективную точку зрения на какой-либо вопрос в ироничной форме, но при этом уже считаются частью реальности для подрастающего поколения $[19,22]$. Таким образом, символы являются вплетенными в структуру современного конструирования действительности, и моделируемый и моделирующий инструменты - именно молодежные СМИ (в силу того, что в рамках анализа гипертекстового пространства социальных сетей невозможно установить глубину поиска).

В рамках работы научного коллектива (в состав которого входят авторы данной работы) отделения социально-гуманитарных наук НИ ТПУ под руководством доктора философских наук Н.А. Лукьяновой при поддержке РФФИ в 2019 г. было проведено исследование, посвященное изучению широкого набора современных источников средств массовой информации с целью систематизации, описания и установления качественных единых коммуникативных концептов визуального образа будущего России в представлении молодежи, который бы учитывал временную личностную и коллективную ориентацию. Авторы данной работы занимались сбором, анализом и последующей формулировкой концепции формируемого в студенческой среде будущего в молодежных журналах развлекательного сектора с выборкой в 5 лет на основе сопряжения методов социологии и философии. В реализованном проекте исследовались процессы конструирования символических паттернов современной России именно с позиции субъективной оценки, выраженной в высказывании личного мнения авторов интервью и репортажей.

Проведенный качественный и количественный анализ показал, что:

1. В силу меняющейся конъектуры отечественного информационного рынка молодежных изданий, выпуск и работа многих журналов (в том числе интернетпорталов) с каждым годом отражает снижение спроса на периодические издания у студентов. Из более чем 30 проанализированных молодежных развлекательных журналов осталось только три издания («Yes!», «Наша молодежь» и «Университетская жизнь» НГУ), которые действуют или действовали за последние 5 лет. К примеру, последний выпуск онлайн-журнала «Университетская жизнь» датируется 13.02.18. Данный факт говорит об отсутствии интереса у молодого поколения к периодическим изданиям и соответственным «уходом» в киберпространство социальных сетей, где смысловое поле неоднозначно и изменчиво.

2. Непосредственно символические репрезентации субъективной оценки будущего на основе полученных данных авторы обозначили следующими маркерами: а) пессимистическая оценка молодежью будущего России; б) пессимистичная оценка личного (собственного) будущего; оптимистичная оценка молодежью будущего России; в) оптимистичная оценка личного будущего; г) предпочтение или значимость настоящего при оценке (конструировании) будущего; д) предпочтение или значимость прошлого при оценке (конструировании) будущего; е) предпочтение или значимость будущего при оценке (конструировании) будущего. Эти маркеры были, в свою очередь, разбиты на конкретные структурные компоненты, которые так или иначе были представлены в статьях проанализированных молодежных развлекательных изданий.

3. В результате контент-анализа (интервью, репортажи и очерки непосредственно студентов) данных изданий по каждому из маркеров впоследствии были выделены композиция и степень выраженности «образа» будущего России в его субъективной форме представления (см. рисунок).

4. Как следует из представленных результатов в структуре субъективизации образов будущего, ключевую роль играет оптимистическая оценка личного будущего молодым поколением, второе место занимают образы, которые продвигаются молодежью 
относительно оптимистической оценки коллективного будущего России, что является характерным положительным признаком социальных флуктуаций, которые отражаются в символических паттернах молодого поколений. К примеру, в исследовании образа России у молодого поколения в 2010 г. результаты были противоположными (характерные паттерны: «разобщенная Россия» и «продажная Россия») [1, с. 87].
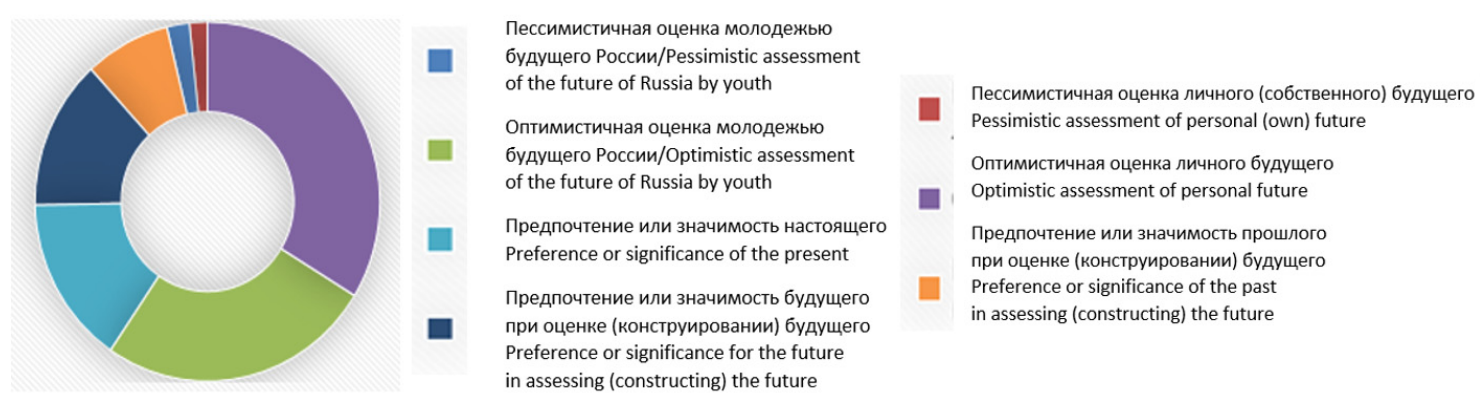

Рисунок. Символические паттерны субъективной оценки собственного и коллективного будущего России молодежью

Figure. Symbolic patterns of subjective assessment of Russia's own and collective future by youth

Выводом проведенного исследования является факт наличия у современной молодежи субъективного положительного «коллективного» образа будущего как самой России, так собственного будущего. Качественное социологические и социальнофилософское исследование «Визуальные репрезентации будущего как фактор конструирования образа России», проведенное в рамках гранта РФФИ позволило описать триггерные точки (оптимистическая оценка личного и коллективного будущего России) в субъективном символизме, где главной конструирующей силой считается непосредственный субъект (интервьюируемый студент) в контексте различных компонентов восприятия настоящего, прошлого и будущего. Как показывают некоторые исследования $[21,23]$, социальные сети и в целом коммуникации непосредственным образом влияют на формирование мнений у молодого поколения через постулируемые символические и логические конструкты. Высокая включенность современной студенческой молодежи в пространство социальных коммуникаций определяет «наполненность» пространства субъективных мнений конкретными паттернами, конструирующими структуру современных представлений относительно коллективного и индивидуального будущего. Совокупное взаимодействие субъективного представления молодежи об образах будущего коррелирующего с усиливающейся ролью социальных медиа отражает положительную конъектуру в студенческом сообществе относительно будущего России в целом, но в большей мере репрезентирует уверенность именно в собственном, личном будущем.

К примеру, на основании статистического исследования журнала «Наша молодежь» (проанализировано 1110 статей) был описан субъективный «образ будущего» в представлении студенческого сообщества согласно маркеру «Карьера», в рамках которого российская молодежь демонстрирует активную позицию в плане создания собственного будущего, принимая на себя «ответственность» за собственный успех. Цели, которые ставит перед собой российская молодёжь прямо коррелируют с уверенностью в собственных силах и при этом демонстрируют нивелирование коллективных целей и приоритетов страны. 


\section{СПИСОК ЛИТЕРАТУРЫ}

1. Матвеева Л.В. Категориальная структура образа России в молодежной аудитории // Вестник НГУ. Серия «Психология». - 2010. - Т. 4. - № 2. - С. 83-98.

2. Сотков О.Л. Образ будущего России в представлении молодежи Тюменской области // Теория и практика общественного развития. - 2017. - № 7. - С. 52-55.

3. Чадаева К.Д. Образ будущего в разных возрастах // Известия Тульского государственного университета. Гуманитарные науки. - 2013. - № 2. - С. 394-340.

4. Дедова В.К. Особенности формирования образа будущего у молодых людей в условиях информационного общества // Социальные явления. - 2013. - № 2. - С. 90-94.

5. Бочарова Е.Е. Конструирование образа будущего учащейся молодежью как аспект ее социального самоопределения // Известия Саратовского университета. Новая серия. Серия «Философия. Психология. Педагогика». - 2010. - Т. 10. - № 3. - С. 68-73.

6. Абульханова К.А. Российский менталитет: кросскультурный и типологический подходы // Российский менталитет: вопросы психологической теории и практики. - М.: ИП РАН, 1997. - С. 7-37.

7. Иноземцев В.Л. Современное постиндустриальное общество: природа, противоречия, перспективы. М.: Логос, 2000. - 304 c.

8. Арляпова Е.В., Конюхова Т.В., Гончарова Н.А. Влияние информационно-коммуникативного пространства на формирование новой индивидуальности // Известия Томского политехнического университета. - 2010. - Т. 317. - № 6. - С. 125-129.

9. Эко У. От Интернета к Гуттенбергу // Новое литературное обозрение. - 1998. - № 4 (32). - С. 5 -14.

10. Хабермас Ю. Понятие индивидуальности // Вопросы философии. - 1989. - № 2. - С. 35-40.

11. Бергер П. Капиталистическая революция (50 тезисов о процветании, равенстве и свободе). - М.: Прогресс, 1994. - 320 с.

12. Лукьянова Н.А. От знака к семиотическим конструктам коммуникативного пространства. - Томск: Изд-во ТПУ, 2010. - 245 с.

13. Степин В.С. От философии науки - к философской антропологии // Познающее мышление и социальное действие / под ред. Н. И. Кузнецовой. - М.: Ф.А.С.-медиа, 2004. - С. 25-30.

14. Величковский Б.М. Когнитивная наука: Основы психологии познания. - М.: Академия, 2006. - 448 с.

15. Виноградов П.Н. Визуальная культура личности: генезис, структура и функции // Известия Российского государственного педагогического университета имени А.И. Герцена. - 2010. - № 136. C. 27-28.

16. Лукьянова Н.A. Ноmo significans в пространстве коммуникаций // Коммуникация: метафизика и метадискурс / под ред. С.В. Клягина, О.Д. Шипуновой. - СПб.: Изд-во Политехнического университета, 2010. - С. 36-38.

17. Конюхова Т.В., Конюхова Е.Т. Жизнестойкость личности как особый паттерн установок освоения социокультурного пространства // Известия Томского политехнического университета. - 2013. T. 322. - № 6. - С. 110-114.

18. Бергер П., Лукман Т. Социальное конструирование реальности. Трактат по социологии знания. - М.: Медиум, 1995. - 323 с.

19. Голубева А.Р., Семилет Т.А. Мем как феномен культуры // Культура и текст. - 2017. - № 3. - С. $193-205$.

20. Лукьянова Н.А., Родионова Е.В., Конюхова Т.В. Социологические основания траектории поддержания психоэмоциональной устойчивости студентов в стрессовых ситуациях // Вестник Томского государственного университета. - 2019. - № 440. - С. 153-159.

21. Zalivanskiy B., Samokhvalova E. Impact of apperception of future on social confidence of younger generation // European Proceedings of Social and Behavioural Sciences. - 2018. - V. 50. - P. 1443-1450. DOI: $10.15405 /$ epsbs.2018.12.176

22. Sorgente A., Lanz M. Emerging Adults' Financial Well-being: a Scoping Review // Adolescent research review. - 2017. - V. 2. - Iss. 4 - P. 255-292. DOI: 10.1007/s40894-016-0052-x

23. Tresno G. Identifying the new influences in the Internet Era: Social Media and social Network Analysis // Journal of Product Innovation Management. - 2016. - V. 33. - Iss. 2. - P. 201-216. DOI: 10.5477/cis/reis.153.23.

Поступила 13.06.2019 2. 
UDC 101.1:316.346.32-053.6(47+57)

\title{
SYMBOLIC PATTERNS OF THE FUTURE SUBJECTIVE VALUE BY CUTTING-EDGE YOUTH GENERATION OF RUSSIA
}

\author{
Anna A. Rusanova, \\ ollyvost@tpu.ru \\ Tatyana V. Konyukhova, \\ konykhova@tpu.ru \\ National Research Tomsk Polytechnic University, \\ 30, Lenin Avenue, Tomsk, 634050, Russia.
}

\begin{abstract}
Anna A. Rusanova, postgraduate student, engineer of organization department, National Research Tomsk Polytechnic University.
\end{abstract}

Tatyana V. Konyukhova, Cand. Sc., associate professor, National Research Tomsk Polytechnic University.

The relevance of the study is determined by the need for cutting-edge young generation of Russia for selfexpression of their perception of the future through social media, in addition, the lack of social and philosophical works devoted to analyzing the interactions between key-elements of the future and its represented symbols. The representative aspect of reflecting the symbolic realities of young people now is the youth generation media, which should be analyzed within the both quantitative and qualitative content analysis in order to determine the symbolic realities of modern Russian youth. The main aim of the research is to determine the symbolic realities of modern Russian youth. A representative feature of the reflection of the symbolic realities of young people at the moment is the youth media, which should be subjected to both quantitative and qualitative content analysis. Methods: content analysis of youth media of an entertaining character along with the methodology of social constructivism to establish relative symbolic patterns of the images of the future in the view of the younger generation. Results. It was found that the process of constructing the «image of the future» concept occurs at a subjective level, and the symbol, as a fragment of thinking, is reflected in modern youth media, within which the processes of symbolic dynamics reflect and define the rules for constructing reality. The study allowed describing the trigger points (optimistic value of Russia's personal and common future) in subjective symbolism, where the main constructive force is the direct subject (interviewed the student) in the context of various components. It is argued that the marker "Career» is the main trigger point, which is a key indicator of its own future representation for the young generation.

Key words: Social philosophy, symbol, young generation, image of the future, content analysis.

The reported study was funded by RFBR and EISR according to the research project № 19-011-31182.

\section{REFERENCES}

1. Matveeva L.V. Kategorialnaya struktura obraza Rossii v molodezhnoy auditorii [Categorical structure of the image of Russia in the youth audience]. Vestnik NGU. Seriya «Psikhologiya», 2010, vol. 4, no. 2, pp. 83-98.

2. Sotkov O.L. Obraz budushchego Rossii v predstavlenii molodezhi Tyumenskoy oblasti [The image of the future of Russia as represented by the youth of the Tyumen region]. Teoriya i praktika obshchestvennogo razvitiya, 2017, no. 7, pp. 52-55.

3. Chadaeva K.D. Obraz budushchego v raznykh vozrastakh [The image of the future at different ages]. Izvestiya Tulskogo gosudarstvennogo universiteta. Gumanitarnyye nauki, 2013, no. 2, pp. 394-340.

4. Dedova V.K. Osobennosti formirovaniya obraza budushchego u molodykh lyudey v usloviyakh informatsionnogo obshchestva [Features of the formation of the image of the future in young people in an information society]. Sotsialnye yavleniya, 2013, no. 2, pp. 90-94. 
5. Bocharova E.E. Konstruirovanie obraza budushchego uchashcheysya molodezhyu kak aspekt ee sotsialnogo samoopredeleniya [Designing the image of the future by young people as an aspect of their social selfdetermination]. Izvestiya Saratovskogo universiteta. Novaya seriya. Seriya «Filosofiya. Psikhologiya. Pedagogika», 2010, vol. 10, no. 3, pp. 68-73.

6. Abulkhanova K.A. Rossiyskiy mentalitet: krosskulturny i tipologicheskiy podkhody [Russian mentality: crosscultural and typological approaches]. Rossiyskiy mentalitet: voprosy psikhologicheskoy teorii i praktiki [Russian mentality: questions of psychological theory and practice]. Moscow, IP RAN Publ., 1997. pp. 7-37.

7. Inozemtsev V.L. Sovremennoe postindustrialnoe obshchestvo: priroda, protivorechiya, perspektivy [Modern post-industrial society: nature, contradictions, perspectives]. Moscow, Logos Publ., 2000. 304 p.

8. Arlyapova E.V., Konyukhova T.V., Goncharova N.A. Influence of information and communication space on the formation of a new individuality. Bulletin of the Tomsk Polytechnic University, 2010, vol. 317, no. 6, pp. 125-129. In Rus.

9. Eco U. Ot Interneta k Guttenbergu [From the Internet to Guttenberg]. Novoe literaturnoe obozrenie, 1998, no. 4 (32), pp. 5-14.

10. Khabermas Yu. Ponyatie individualnosti [The notion of individuality]. Voprosy filosofii, 1989, no. 2, pp. 35-40.

11. Berger P. Kapitalisticheskaya revolyutsiya (50 tezisov o protsvetanii, ravenstve $i$ svobode) [The Capitalist Revolution (50 theses on prosperity, equality and freedom)]. Moscow, Progress Publ., 1994. 320 p.

12. Lukyanova N.A. Ot znaka k semioticheskim konstruktam kommunikativnogo prostranstva [From the Sign to the Semiotic Constructs of the Communicative Space]. Tomsk, Tomsk Polytechnic University Publ. house, 2010. 245 p.

13. Stepin V.S. Ot filosofii nauki - k filosofskoy antropologii [From the philosophy of science - to philosophical anthropology]. Poznayushchee myshlenie $i$ sotsialnoe deystvie [Cognitive thinking and social action]. Ed. by N.I. Kuznetsova. Moscow, F.A.S.-media Publ., 2004. pp. 25-30.

14. Velichkovsky BM. Kognitivnaya nauka: Osnovy psikhologii poznaniya [Cognitive science: Fundamentals of the psychology of knowledge]. Moscow, Akademiya Publ., 2006. 448 p.

15. Vinogradov P.N. Vizualnaya kultura lichnosti: genezis, struktura i funktsii [Visual culture of personality: genesis, structure and fuctions]. Nauchny zhurnal Rossiyskogo gosudarstvennogo pedagogicheskogo universiteta im. A.I. Gertsen, 2010, no. 136, pp. 27-28.

16. Lukyanova N.A. Homo significans v prostranstve kommunikatsiy [Homo significans in the space of communications]. Kommunikatsiya: metafizika i metadiskurs [Communication: metaphysics and metadiscourse]. Eds. S.V. Klyagin, O.D. Shipunova. St. Petersburg, Polytechnic University Publ., 2010. pp. 36-38.

17. Konyukhova T.V., Konyukhova E.T. Personality Resilience as a Special Pattern of Attitudes for the Development of Socio-Cultural Space. Bulletin of the Tomsk Polytechnic University, 2013, vol. 322, no. 6, pp. 110-114. In Rus.

18. Berger P., Lukman T. Sotsialnoe konstruirovanie realnosti. Traktat po sotsiologii znaniya [Social Construction of Reality: a Treatise on the Sociology of Knowledge]. Moscow, Medium Publ., 1995. pp. 323.

19. Golubeva A.R., Semilet T.A. Mem kak fenomen kultury [Mem as a cultural phenomenon]. Kultura i tekst, 2017, no. 3, pp. 193-205.

20. Lukyanova N.A., Rodionova E.V., Konyukhova T.V. Sociological Reasons of the Trajectory for Supporting the Students' Psychoemotional Stability in Stressful Situations. Tomsk State University Journal, 2019, no. 440, pp. 153-159. In Rus.

21. Zalivanskiy B., Samokhvalova E. Impact of apperception of future on social confidence of younger generation. European Proceedings of Social and Behavioural Sciences, 2018, vol. 50, pp. 1443-1450. DOI: $10.15405 /$ epsbs.2018.12.176

22. Sorgente A., Lanz M. Emerging Adults' Financial Well-being: A Scoping Review. Adolescent research review, 2017, vol. 2, Iss. 4, pp. 255-292. DOI: 10.1007/s40894-016-0052-x

23. Tresno G. Identifying the new influences in the Internet Era: Social Media and social Network Analysis. Journal of Product Innovation Management, 2016, vol. 33, Iss. 2, pp. 201-216. DOI: $10.5477 /$ cis/reis. 153.23 .

Received: 13 June 2019. 